\title{
Systematic Evaluation of Key L-Carnitine Homeostasis Mechanisms during Postnatal Development in Rat
}

\author{
Binbing Ling ${ }^{1}$, Caroline Aziz $^{2}$ and Jane Alcorn ${ }^{1 *}$
}

\begin{abstract}
Background: The conditionally essential nutrient, L-carnitine, plays a critical role in a number of physiological processes vital to normal neonatal growth and development. We conducted a systematic evaluation of the developmental changes in key L-carnitine homeostasis mechanisms in the postnatal rat to better understand the interrelationship between these pathways and their correlation to ontogenic changes in L-carnitine levels during postnatal development.

Methods: mRNA expression of heart, kidney and intestinal L-carnitine transporters, liver $\gamma$-butyrobetaine hydroxylase (Bbh) and trimethyllysine hydroxylase ( $(\mathrm{mmlh})$, and heart carnitine palmitoyltransferase (Cpt) were measured using quantitative RT-PCR. L-Carnitine levels were determined by HPLC-UV. Cpt and Bbh activity were measured by a spectrophotometric method and HPLC, respectively.

Results: Serum and heart L-carnitine levels increased with postnatal development. Increases in serum L-carnitine correlated significantly with postnatal increases in renal organic cation/carnitine transporter 2 (Octn2) expression, and was further matched by postnatal increases in intestinal Octn 1 expression and hepatic $\gamma$-Bbh activity. Postnatal increases in heart L-carnitine levels were significantly correlated to postnatal increases in heart Octn2 expression. Although cardiac high energy phosphate substrate levels remained constant through postnatal development, creatine showed developmental increases with advancing neonatal age. mRNA levels of Cpt1b and Cpt2 significantly increased at postnatal day 20, which was not accompanied by a similar increase in activity.
\end{abstract}

Conclusions: Several L-carnitine homeostasis pathways underwent significant ontogenesis during postnatal development in the rat. This information will facilitate future studies on factors affecting the developmental maturation of L-carnitine homeostasis mechanisms and how such factors might affect growth and development.

Keywords: L-Carnitine, Homeostasis, Postnatal development, Rat

\section{Introduction}

L-Carnitine is a conditionally essential nutrient that functions in a number of physiological processes vital to normal neonatal growth and development [1]. With transition to extrauterine life the carbohydrate rich, low-fat umbilical blood supply is replaced by the high fat, low glucose diet of the breast milk. This switch in nutrition source requires rapid physiological adaptations in the newborn to enhance gluconeogenic processes and fatty acid oxidation pathways to meet the energy

\footnotetext{
* Correspondence: jane.alcorn@usask.ca

${ }^{1}$ College of Pharmacy and Nutrition, University of Saskatchewan, 110 Science Place, Saskatoon, SK S7N 5C9, Canada

Full list of author information is available at the end of the article
}

demands of developing neonate. L-Carnitine plays an important role in the enhancement of fatty acid utilization during this adaptive period and throughout postnatal development [1]. By regulating the movement of long chain fatty acids into mitochondria and making them available for $\beta$-oxidation, L-carnitine has an obligatory function in cellular energy production. Furthermore, L-carnitine has a role in the removal of toxic fatty acyl-CoA metabolites from the mitochondria to maintain an appropriate balance between free carnitine and its acylated forms [2]. This vital role in cellular metabolism identifies L-carnitine as essential to the maintenance of normal mitochondrial function and in the prevention of disease [2]. Any disruption in the 
L-carnitine homeostatic processes during postnatal maturation might adversely impact the developing and growing neonate [3].

L-Carnitine homeostasis represents a balance between 1) de novo biosynthesis, 2) intestinal absorption from dietary sources, 3) uptake and release by the tissues, and 4) renal reabsorption [4]. In early postnatal life, L-carnitine biosynthesis is limited as a result of immature $\gamma$-butyrobetaine hydroxylase activity (Bbh) (approximately 10-12\% adult levels), the enzyme that mediates the last step in L-carnitine biosynthesis [5-7], but not trimethyllysine hydroxylase (Tmlh) activity, the first enzyme in L-carnitine biosynthesis [6]. The activity of $\mathrm{Bbh}$ increases with age and reaches adult values later in postnatal development $[6,8]$. Delayed Bbh maturation suggests a reliance on dietary L-carnitine sources particularly during the immediate postnatal period.

Dietary L-carnitine is absorbed across the gastrointestinal mucosa by active transport systems at the luminal enterocytic membrane [4]. Membrane transporters, in particular the organic cation/carnitine transporters (Octn1, Octn2, and Octn3), also mediate the tissue distribution and renal reabsorption of L-carnitine and thus play a critical role in L-carnitine homeostasis [9-11]. Of these Octn transporters, Octn2 is the major high affinity sodium-dependent L-carnitine transporter [12,13] that plays a major role in regulating plasma and tissue pools of L-carnitine. Octn transporters might undergo changes in expression with postnatal maturation, but limited data are available on their ontogeny in different tissues $[12,14,15]$.

As major components of the L-carnitine shuttle system, L-carnitine acyltransferase enzyme (Cpt) systems play important roles in fatty acid metabolism and energy production and maintaining an appropriate balance between free and acylated fatty acids [16]. Cpt1 on the mitochondrial outer membrane catalyses the first step of mitochondrial import of long chain fatty acids by converting them from fatty acyl-CoA to acylcarnitines [17]. On the inner mitochondrial membrane Cpt2 reconverts the acylcarnitines to the respective CoA esters releasing free L-carnitine and making fatty acids available for $\beta$ oxidation [18]. Limited information is also available on the ontogeny of Cpt enzymes.

Given our limited understanding of the ontogenesis of L-carnitine homeostasis pathways, we conducted a systematic evaluation of the developmental changes in tissue L-carnitine levels, tissue Octn mRNA expression and immunohistochemistry, liver Bbh expression and activity, heart Cpt1b and Cpt2 expression and activity, and heart high energy phosphate compounds at different postnatal ages with consideration of the known maturation of L-carnitine biosynthesis for the rat [19]. At each postnatal age, these evaluations were conducted in tissues sampled from the same animal to avoid the expected interindividual variability and replicated such that the sample size was four animals per postnatal age group. Such a systematic evaluation is important for investigations into environmental and pathophysiological factors that might impact the normal maturation of these processes and the long-term impact on health and risk for chronic disease, which is a principal objective of our laboratory.

\section{Material and Methods}

\section{Animals and Chemicals}

Female Sprague-Dawley rats ordered at different gestation stages were obtained from Charles River Canada (St. Constant, PQ) and were housed singly in a temperature and humidity controlled facility $\left(22{ }^{\circ} \mathrm{C} \pm 2{ }^{\circ} \mathrm{C}\right)$ on a 12-hour light:dark cycle $(0700 \mathrm{~h}-1900 \mathrm{~h})$. All rats were allowed a 7-day acclimatization period and had free access to food (Prolab ${ }^{\circledR}$ RMH 3000, Purina, Inc., Richmond, IN) and water throughout the study. The dams were closely monitored near parturition to identify the exact time of birth. At birth, the litter size was equalized to 10 pups per dam. The dam was considered the experimental unit $(n=6)$ and blood and tissues were pooled from 5 pups from each dam to carry out the various analyses. Rat pups at postnatal day (PD) 4, 8, 11 and 20 were anaesthetized with isoflurane, and blood (200 $500 \mu \mathrm{L}$ depending on age) was collected by intracardiac puncture. The rats were immediately sacrificed and heart, intestine, kidney, and liver were rapidly excised and flash-frozen in liquid nitrogen with storage at $-80^{\circ}$ $\mathrm{C}$ until analysis. All procedures were conducted in accordance with the Canadian Council of Animal Care guidelines for the care and use of laboratory animals and were approved by the Animal Research Ethics Board of the University of Saskatchewan.

RNeasy Midi kits were obtained from Qiagen Inc. (Mississauga, ON). The QuantiTect SYBR Green RTPCR kit was from Applied Biosystems (Foster City, CA). The Advanced Protein Assay kit was obtained from Fluka (Buchs, Switzerland). L-Carnitine and other chemicals not otherwise specified were obtained from Sigma-Aldrich (St. Louis, MO) and were the highest purity grade available.

\section{L-Carnitine Analysis in Serum and Heart}

Serum and heart L-carnitine was quantified by HPLCUV with pre-column derivatization according to Feng et al. [20]. Briefly, the pooled heart samples were homogenized with phosphate buffer $(50 \mathrm{mM}, \mathrm{pH} 7.4)$ in a ratio of $50 \mathrm{mg}$ tissue: $250 \mu \mathrm{L}$ buffer. The homogenate was centrifuged at $2500 \times g$ for $10 \mathrm{~min}$ at $4{ }^{\circ} \mathrm{C}$. The supernatant or serum $(20 \mu \mathrm{L})$ sample was precipitated using acetonitrile and methanol (9:1 v/v). A $300 \mathrm{mg}$ 
mixture of $\mathrm{Na}_{2} \mathrm{HPO} 4$ and $\mathrm{Ag}_{2} \mathrm{O}$ (9:1 wt/wt) and $300 \mathrm{mg}$ of $\mathrm{KH}_{2} \mathrm{PO} 4$ were added followed by a $1 \mathrm{~h}$ vortex mixing. Derivatization reagent $(40 \mathrm{mg} / \mathrm{mL} \quad \rho$-bromophenacyl bromide with $50 \mu \mathrm{L} 40$ \% tetrabutylammonium hydroxide solution) was added into the organic extract. The reaction mixture was incubated at $60{ }^{\circ} \mathrm{C}$ for $2 \mathrm{~h}$ followed by centrifugation at $12,000 \times g$ for $15 \mathrm{~min}$. L-Carnitine was analyzed using a Hewlett Packard 1050 HPLC system with Diode Array Detector, Quaternary Pump and Autosampler. Samples $(10 \mu \mathrm{L})$ were injected onto a CN (cyano) column (HyperClone $5 \mu \mathrm{m}, 250 \times 4.6 \mathrm{~mm}$, Phenomenex, Torrance, CA) with detection wavelength set at $260 \mathrm{~nm}$. The mobile phase $(90 \%$ acetonitrile/10 mM citric-phosphate buffer, $\mathrm{pH}$ 3) was delivered at a flow rate of $1 \mathrm{~mL} / \mathrm{min}$. The standard curve range was linear $\left(\mathrm{r}^{2}>0.99\right)$ between $2.5-40 \mu \mathrm{mol} / \mathrm{L}$. Intra- and interassay accuracy and precision ranged from $6 \%-14 \%$.

\section{Heart Carnitine Palmitoyltransferase (Cpt) Enzyme Activities}

Heart Cpt enzyme activities were measured using the spectrophotometric method described by Bieber et al. [21]. Briefly, frozen heart tissue was homogenized in $10 \%$ (wt/v) homogenization buffer (20 mM HEPES, $140 \mathrm{mM} \mathrm{KCl}, 10 \mathrm{mM}$ EDTA and $5 \mathrm{mM} \mathrm{MgCl} 2, \mathrm{pH}$ 7.4) supplemented with $3 \mathrm{mg}$ nagarse using Polytron homogenizer (Brinkmann Instruments, Rexdale, Canada). The homogenate was then centrifuged at $500 \times g$ for $10 \mathrm{~min}$ at $4{ }^{\circ} \mathrm{C}$. The supernatant was collected in new tubes and centrifuged at $9000 \times g$ for $35 \mathrm{~min}$ at $4{ }^{\circ} \mathrm{C}$. The pellet was then washed with the homogenization buffer without nagarse and centrifuged at $9000 \times g$ for $35 \mathrm{~min}$ at $4{ }^{\circ} \mathrm{C}$. The washed pellet was resuspended in $200 \mu \mathrm{L}$ homogenization buffer without nagarse. Protein concentrations were measured using the Advanced Protein Assay kit with bovine serum albumin as standard. The optimal protein concentration and reaction time to give linear product formation were initially determined. To determine total Cpt activity $20 \mu \mathrm{g}$ protein was assayed in $200 \mu \mathrm{L} \mathrm{mL}$ reaction buffer containing $20 \mathrm{mM}$ HEPES, $1 \mathrm{mM}$ EGTA, $220 \mathrm{mM}$ sucrose, $40 \mathrm{mM} \mathrm{KCl}, 0.1 \mathrm{mM}$ 5,5'-dithio-bis (2-nitrobenzoic acid) (DTNB), $1.3 \mathrm{mg} / \mathrm{mL}$ $\mathrm{BSA}$, and $40 \mu \mathrm{M}$ palmitoyl-CoA, $\mathrm{pH}$ 7.4. The reactions were initiated by adding $1 \mathrm{mM} \mathrm{L}$-carnitine and read at $412 \mathrm{~nm}$ after $5 \mathrm{~min}$ incubation at $37{ }^{\circ} \mathrm{C}$ using Synergy HT Multi-Mode Microplate Reader (Biotek instrument, USA). Cpt2 activity was determined using the same reaction conditions as total Cpt except $10 \mu \mathrm{L}(0.2 \mathrm{mM})$ Cpt1 inhibitor, malonyl-CoA, was added into $200 \mu \mathrm{L}$ of the reaction mixtures to obtain a final concentration of $10 \mu \mathrm{M}$. Cpt1 activity was calculated by subtracting the Cpt2 activity from the total Cpt activity. The Cpt activity was calculated as amount of CoASH released per min per mg protein, which is based on the 5-thio-2-nitrobenzoate formation from CoASH-DNTB reaction. The extinction coefficient for 5-thio-2-nitrobenzoate was $13.6 \mathrm{mM} / \mathrm{cm}$ and was used to calculate enzyme activity [22].

\section{Liver $\mathrm{p}$-Butyrobetaine Hydroxylase (Bbh) Enzyme Activity}

The liver tissue was homogenized in homogenization buffer consisting of $300 \mathrm{mM}$ sucrose, $1 \mathrm{mM}$ EGTA, and $50 \mathrm{mM}$ Tris, $\mathrm{pH} 7.5$ using 1:4 mass to volume ratio. The homogenate was then centrifuged at $13,000 \times g$ for $30 \mathrm{~min}$ at $4{ }^{\circ} \mathrm{C}$. The supernatant was collected and centrifuged at $100,000 \times \mathrm{g}$ for $1 \mathrm{~h}$ at $4{ }^{\circ} \mathrm{C}$. $300 \mu \mathrm{L}$ of the supernatant representing the cytosolic fraction containing Bbh was then transferred into a dialysis tubing cellulose membrane (molecular weight cutoff of 12,000 Da, D9777, Sigma, USA), and submerged in $5 \mathrm{~L}$ dialysis buffer $(75 \mathrm{mM} \mathrm{KCl}, 0.1 \mathrm{mM}$ DTT and $0.5 \mathrm{mM}$ EDTA in sodium phosphate buffer, $\mathrm{pH} 7.4$ ) overnight at $4{ }^{\circ} \mathrm{C}$. The dialyzed sample $(20 \mu \mathrm{L})$ was tested for L-carnitine residue and the remaining dialysate was stored at $-80{ }^{\circ} \mathrm{C}$ for Bbh testing. The optimal protein concentration, substrate concentration and reaction time to give linear product formation was determined for each age group. For determination of Bbh activity in rat pup liver, $1 \mathrm{~mL}$ reaction buffer consisting of $0.2 \mathrm{mM} \gamma$-butyrobetaine, $20 \mathrm{mM}$ potassium chloride, $3 \mathrm{mM}$ 2-oxoglutarate, $10 \mathrm{mM}$ sodium ascorbate, $0.4 \mathrm{mg} / \mathrm{mL}$ catalase in $20 \mathrm{mM}$ potassium phosphate buffer $\mathrm{pH} 7.0$ was prepared. The reaction was initiated by adding $2 \mu \mathrm{L}$ ferrous ammonium sulfate [23] (final concentration: $0.25 \mathrm{mM}$ ) and $20 \mu \mathrm{L}$ dialyzed enzyme into $78 \mu \mathrm{L}$ reaction buffer and incubated for $25 \mathrm{~min}$ at $37{ }^{\circ} \mathrm{C}$ using a Boekel/Grant Orbital and Reciprocating Water Bath (Model ORS200, Expotech, USA). The reaction was then terminated by adding 10 times the volume of acetonitrile:methanol (9:1). The mixture was centrifuged at $13,000 \times g$ for $2 \mathrm{~min}$ and the supernatant was used for L-carnitine analysis by HPLC.

\section{Total mRNA Isolation and Quantitative RT-PCR Analysis}

Total mRNA was extracted from different tissues using Qiagen RNeasy Midi Kits according to manufacturer instructions. RNA purity and quantity were determined spectrophotometrically by measurement at $260 \mathrm{~nm}$ and the $\mathrm{OD}_{260} / \mathrm{OD}_{280}$ ratio, respectively, with a Synergy HT Multi-Mode Microplate Reader (Biotek instrument, USA). Total RNA was stored at $-80{ }^{\circ} \mathrm{C}$ until analysis. Gene sequences were obtained from the National Center for Biotechnology Information GeneBank and specific primers were designed using Primer3 software (Whitehead Institute for Medical Research. Primer 3: http:// frodo.wi.mit.edu/primer3/) (Table 1). Quantitative RTPCR (QRT-PCR) analysis was carried out using a QuantiTect SYBR Green RT-PCR kit and an Applied Biosystems 7300 Real-Time PCR system. The QRT-PCR 
Table 1 Primer sequences for quantitative RT-PCR of rat enzymes and transporters involved in L-carnitine homeostasis

\begin{tabular}{llll}
\hline Gene & $\begin{array}{l}\text { Accession } \\
\text { Number }\end{array}$ & \multicolumn{2}{c}{ Primers } \\
\cline { 3 - 4 } & Forward & Reverse \\
\hline B-actin & NM_031144 & agcgtggctacagcttcacc & tgccacaggattccataccc \\
\hline Octn1 & NM_022270 & catggctgtgcagactgg & gcaccatgtagccgatgg \\
\hline Octn2 & NM_019269 & ggcgcaaccacagtatcc & ggggctttccagtcatcc \\
\hline Octn3 & NM_019723 & gacaccgtgaacctgagc & ccatccaggcagttctcc \\
\hline Cpt1b & NM_013200 & cagccatgccaccaagatc & aagggccgcacagaatcc \\
\hline Cpt2 & NM_012930 & gctccgaggcgtttctca & tggccgttgccagatagc \\
\hline Bbh & NM_022629 & acgatggggcagagtcc & ctggcctcctgagaaaagc \\
\hline Tmlh & NM_133387 & aatgtccctcccactcagg & tcggtatggcgatctaggg \\
\hline
\end{tabular}

Octn, organic cation/carnitine transporter; $\mathrm{Cpt}$, carnitine palmitoyltransferase; $\mathrm{Bbh}, \mathrm{\gamma}$-butyrobetaine hydroxylase; $\mathrm{Tmlh}$, trimethyllysine hydroxylase.

protocol was carried out according to manufacturer's instructions. The protocol consisted of reverse transcription ( 1 cycle at $48^{\circ} \mathrm{C}, 30$ minutes), PCR initial activation step ( 1 cycle at $95{ }^{\circ} \mathrm{C}, 15$ minutes), three-step thermalcycling (40 cycles; denaturing at $94{ }^{\circ} \mathrm{C}, 15$ seconds, annealing at $60{ }^{\circ} \mathrm{C}, 30$ seconds, and primer extension at $60{ }^{\circ} \mathrm{C}$ for 30 seconds), and a melt curve analysis from $65{ }^{\circ} \mathrm{C}-95^{\circ} \mathrm{C}$ at $0.5{ }^{\circ} \mathrm{C} /$ second.

\section{Validation of Primers}

Quantitative RT-PCR assays were initially optimized to give PCR efficiency between 1.9-2.1 (as determined by a 3 -point standard curving using serial dilutions of control RNA with a slope range of -2.9 to -3.5 ) and a single melt-peak corresponding to the appropriate PCR product as verified by $2 \%$ agarose gel electrophoresis. In addition, the amplification efficiency of each target and $\beta$-actin was determined by constructing a standard curve from the crossing point $\left(\mathrm{C}_{\mathrm{T}}\right)$ value and RNA concentration. The target genes and $\beta$-actin were then amplified using the same diluted samples. The $\Delta \mathrm{C}_{\mathrm{T}}$ values were calculated (i.e. the difference between the target gene $C_{T}$ and $\beta$-actin $\left.C_{T}\right)$. The slope from log RNA concentration versus $\Delta \mathrm{C}_{\mathrm{T}}$ was close to zero $(<0.1)$. Only primers giving PCR amplification close to $100 \%$ and relative efficiencies between the target and $\beta$-actin that were approximately equal were used in our experiment.

\section{Heart High Energy Phosphate Substrate Determination}

The heart high energy phosphate substrate levels including creatine $(\mathrm{Cr})$, creatine phosphate $(\mathrm{CrP})$, ATP, ADP and AMP were measured with HPLC-UV method as described by Olkowski et al. [24]. The heart samples were homogenized in $0.7 \mathrm{M}$ ice-cold perchloric acid (MW $100.46 \mathrm{D}$ ) with a final concentration $100 \mathrm{mg} / \mathrm{mL}$. The homogenate was centrifuged at 12,000 rpm for 5 minutes. The supernatant was collected and neutralized with $2 \mathrm{M}$ potassium hydroxide to bring $\mathrm{pH}$ near to 7.0.
The supernatant was then filtered through a $0.45 \mu \mathrm{m}$ filter (Nonsterile Syringe Filter Nylon, Chromatographic Specialties Inc. Brockville, Ontario, Canada) and $10 \mu \mathrm{L}$ was injected onto a $3 \mu \mathrm{m}$ Luna C18 (Phenomenex, Torrance, CA) column using gradient flow conditions. Two mobile phase components used included $20 \mathrm{mM}$ potassium phosphate buffer $(\mathrm{pH} 7.0)$ and $100 \%$ methanol. The gradient was $100 \%$ phosphate buffer from 0$6.5 \mathrm{~min}, 100 \%$ methanol from $6.5-12.5 \mathrm{~min}$, and $100 \%$ phosphate buffer from 12.5 to $25 \mathrm{~min}$ for column reequilibration, which was sufficient to achieve stable baseline conditions. The high-energy phosphate substrates including $\mathrm{CrP}, \mathrm{Cr}$, ATP, ADP and AMP were monitored at $210 \mathrm{~nm}$. The standard curve range was from $6.25-100 \mu \mathrm{g} / \mathrm{mL}$ and the limit of detection was $0.078 \mu \mathrm{g} / \mathrm{mL}$ for ATP and $0.312 \mu \mathrm{g} / \mathrm{mL}$ for ADP and AMP. Intra- and interassay accuracy and precision ranged from $4.2 \%$ to $14.5 \%$.

\section{Immunohistochemistry}

Intestine and kidney from neonatal rat pups were rapidly harvested and fixed by immersion in $4 \%$ paraformaldehyde. Paraffin imbedded sections $(5 \mu \mathrm{m})$ were prepared by standard procedures and sections were incubated with Octn antibodies (1:100) (Alpha Diagnostic International) for $1 \mathrm{~h}$ followed by $(\mathrm{H}+\mathrm{L})$-peroxidase-conjugated affinity-pure goat anti-rabbit IgG (1:500) for $30 \mathrm{~min}$. Immunoreactions were visualized by using VIP Substrate kit for peroxidase (Vector Laboratories) according to manufacturer instructions. Non-specific binding was tested by using premixed control peptide with the respective Octn antibodies. For negative controls, only secondary antibody was applied to the slides.

\section{Statistical Analysis}

All data are reported as mean \pm SEM. One-way ANOVA with Tukey's post hoc test was used for the comparisons between ages. A $P<0.05$ was chosen as the level of statistical significance. Pearson's correlation coefficients were computed to quantify the association between heart L-carnitine concentration and heart Octn2 mRNA expression levels as well as serum L-carnitine concentration and kidney Octn2 mRNA expression.

\section{Results}

To examine the ontogenesis of critical components of the L-carnitine homeostasis pathway we conducted an mRNA expression and activity analysis of various components of the homeostasis pathway in different tissues of rat pups of different postnatal ages. Serum free L-carnitine concentrations (Figure 1A) increased significantly between postnatal day (PD) 4 and PD11 (PD11 L-carnitine concentrations were approximately $20 \%$ higher than PD4) and stayed reasonably stable after PD11. 

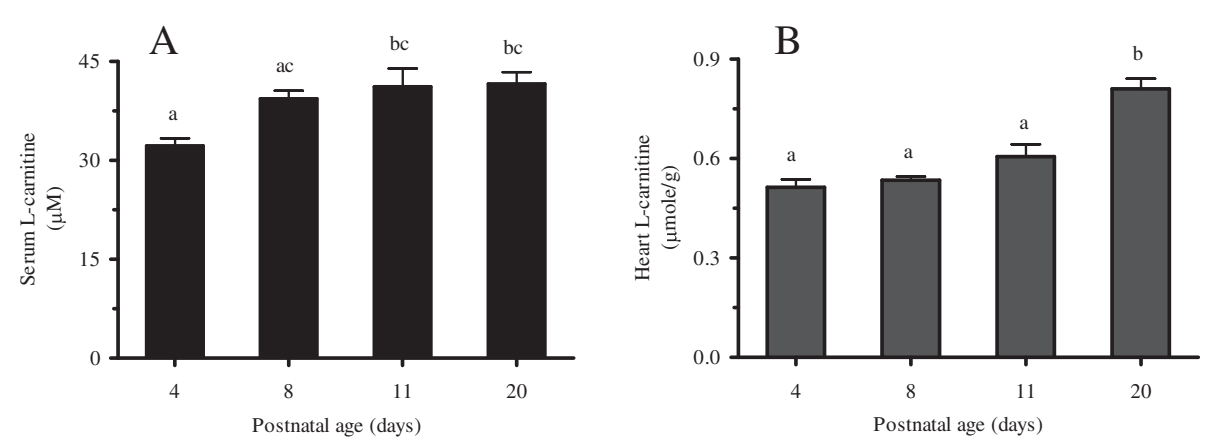

Figure 1 Mean \pm SEM free L-carnitine concentration in rat $(A)$ serum and $(B)$ heart tissue $(n=6)$ at postnatal day $4,8,11$, and 20 . L-Carnitine concentration was determined using HPLC-UV as described in text. One-way ANOVA with Tukey's post hoc test was used for the comparisons between ages and bars with the same letters indicate no significant difference, $P<0.05$.

Heart free L-carnitine concentrations (Figure 1B) were relatively similar at PD4, PD8 and PD11, but a significant increase was observed between PD11 and PD20 (heart L-carnitine concentrations were approximately 50 \% greater at PD20 relative to PD4).

mRNA expression of key L-carnitine transporters, the Octns, were evaluated in the heart, kidney, and intestine by QRT-PCR. Generally, heart Octn1 mRNA expression (Figure 2A) remained constant, except at PD8, where expression was statistically higher than all other PD age groups. Heart Octn2 expression (Figure 2A) increased postnatally (approximately $100 \%$ increase in expression at PD11 relative to PD4), although increases in expression after PD11 were not statistically significant. Although not statistically significant, heart Octn3 mRNA expression (Figure 2A) was lowest at PD4 while expression was approximately $200 \%$ higher at PD8 and remained relatively constant thereafter. A strong $(\mathrm{r}=0.823)$ and significant correlation $(P<0.05) \quad$ (Figure 3B) was observed between heart free L-carnitine concentrations and heart Octn2 mRNA expression in rat pups at different postnatal age groups.

In the kidney, Octn1 and Octn3 mRNA expression (Figure 2B) was relative stable throughout postnatal development, although PD11 demonstrated a statistically significant decrease in expression relative to all other PD age groups. This consistent result between Octn1 and Octn3 likely has limited importance as it probably results from expected interindividual variation and the use of a destructive sampling strategy. Kidney Octn2 expression (Figure 2B) increased in the postnatal period, although increases in expression after PD11 were not statistically significant. Serum free L-carnitine concentrations were significantly correlated $(\mathrm{r}=0.462)$ to kidney Octn2 mRNA expression $(P<0.05)$ (Figure 3A) in rat pups at different postnatal age groups.

In the intestine, Octn1 mRNA expression (Figure 2C) was low at PD4 but demonstrated a statistically significant increase (approximately $200 \%$ ) at PD8. Expression at PD20 was similar to PD8, although PD11 demonstrated a statistically significant decrease in expression relative to PD8 and PD20. Relative to Octn1 mRNA expression, intestinal Octn2 and Octn3 mRNA expression (Figure 2C) was high in the early postnatal period. Expression of Octn2 and Octn3 remained relatively constant through the remaining postnatal period.

The postnatal increase in liver Bbh mRNA expression generally mirrored the increase in Bbh activity (Figure 4). Although not statistically significant, Bbh mRNA expression (Figure 4A) increased approximately $50 \%$ between PD4 and PD8 with a statistically significant increase (more than $100 \%$ ) between PD8 and PD20. An approximately $400 \%$ increase in liver Bbh activity (Figure 4B) was observed between PD4 and PD11 and activity remained relatively constant thereafter.

Heart Cpt $1 \mathrm{~b}$ and Cpt 2 and liver Tmlh mRNA expression (Figure 5A and 5B) remained constant in the early postnatal period with significant increases in expression (approximately $50 \%$ ) occurring only between PD11 and PD20 for Cpt enzymes, while no change in Tmlh mRNA expression was observed with postnatal age. Despite this increase in Cpt mRNA expression in the late postnatal period, no significant differences in Cpt enzyme activity (Figure 6) were found at all examined postnatal ages. In addition, heart high energy phosphate concentrations (Figure 7) remained relatively constant through postnatal development. The heart concentrations of creatine (Figure 7) increased significantly during postnatal development. An almost $250 \%$ increase in heart creatine concentrations was observed between PD4 and PD8 and a more than $100 \%$ increase between PD8 and PD20. Creatine phosphate levels in postnatal cardiac tissue (Figure 7) remained relatively constant at all postnatal age groups.

Immunohistochemical staining with Octn antibodies was performed to determine Octn expression in kidney, intestine and heart in situ,. However, staining for Octn 

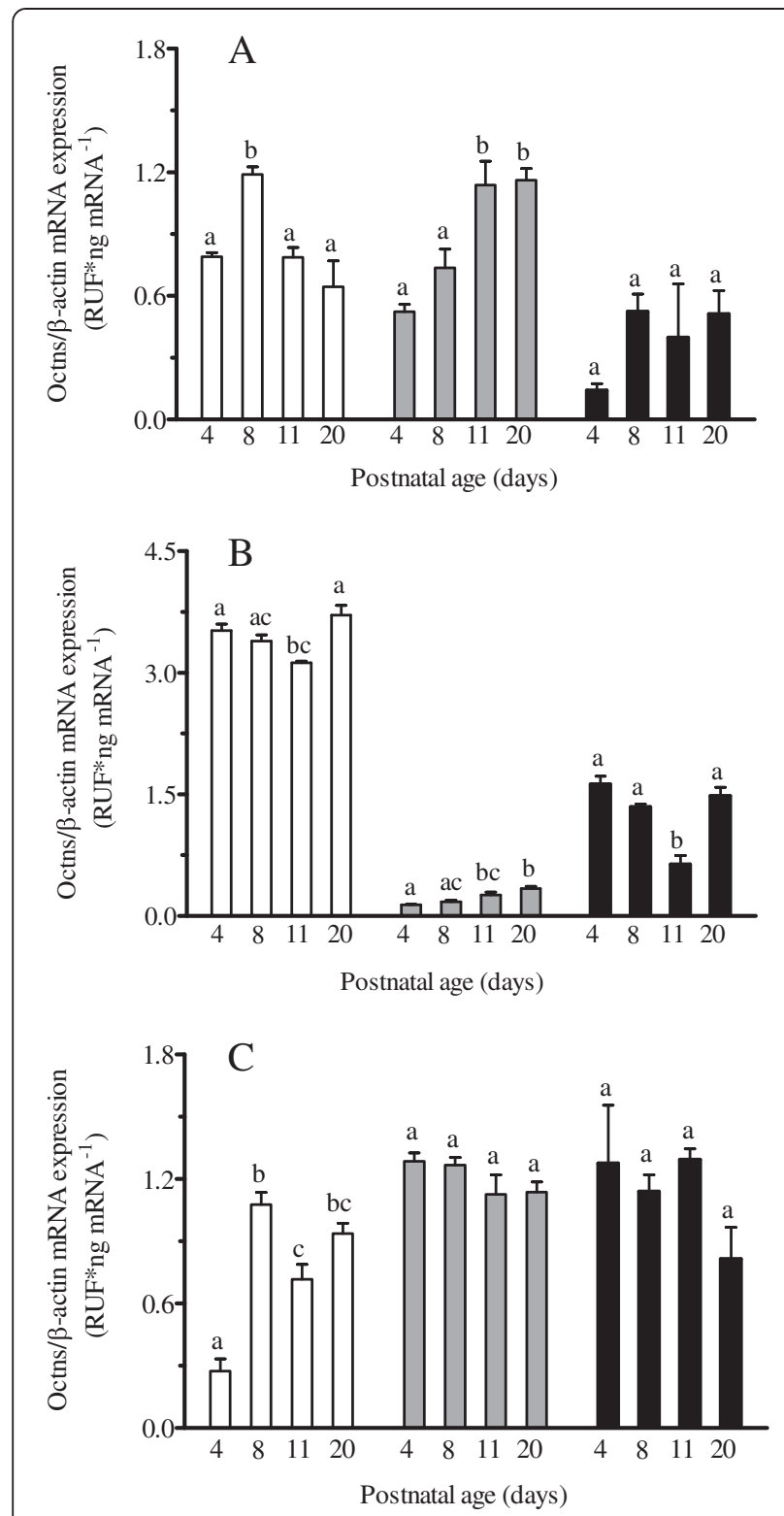

Figure 2 Mean \pm SEM organic cation/carnitine transporter (Octn) mRNA expression (Octn1 - white bar; Octn2 - light grey bar; Octn3 - dark grey bar) in rat (A) heart, (B) kidney, and (C) intestine at postnatal day $4,8,11$, and $20(n=6)$. mRNA expression was normalized to $\beta$-actin and fold difference (FD) was determined by using $2^{-\Delta \Delta C T}$ method. One-way ANOVA with Tukey's post hoc test was used for the comparisons between ages and bars with the same letters indicate no significant difference, $P<0.05$.

transporters in PD11 could not be distinguished from control and no further evaluations were conducted.

\section{Discussion}

During postnatal development, a number of nutrient homeostasis pathways undergo ontogenesis to satisfy the nutrient requirements for growth and development.
Although many of the developmental changes in these nutrient homeostasis pathways are genetically programmed, exogenous factors such as dietary components, environmental compounds and therapeutic drugs might affect their maturation. Our laboratory is interested in the developmental outcomes of interactions between drugs and nutrients that share the same absorption and/or disposition (i.e. distribution, elimination mechanisms) mechanisms. Our investigations began with L-carnitine homeostasis pathways and we systemically evaluated the ontogeny of key L-carnitine homeostasis pathways in the rat. Such information can help us to further understand the impact of exogenous factors on the maturation of nutrient homeostasis processes and the possible long-term consequences of drugnutrient interactions during ontogeny.

In mammals, fatty acid oxidation becomes the main source of energy for many tissues with transition to extrauterine life [25]. Mitochondrial fatty acid utilization, though, requires a sufficient supply of L-carnitine to shuttle long-chain fatty acids across the mitochondrial membrane making them available for $\beta$-oxidation [2]. The maternal circulation supplies L-carnitine to the developing fetus. During late gestation, L-carnitine concentrations significantly increase in fetal tissues and this storage of L-carnitine assures adequate levels in the immediate postpartum period $[9,26]$. These tissue stores quickly become depleted due to the immaturity of many of the L-carnitine homeostasis mechanisms and maintenance of L-carnitine concentrations requires an exogenous source (i.e. milk) of L-carnitine [9]. In our study, postnatal increases in serum free L-carnitine were consistent with levels reported in the literature [27] and these increases correlated with maturation of a number of enzymes and transporter systems that critically determine L-carnitine levels in the body.

Lower serum free L-carnitine levels in the early postnatal period is, in part, due to the limited capacity for endogenous biosynthesis by the young neonate $[5,19]$. As noted in other studies, TLMH mRNA expression remained constant with postnatal development [6] and in agreement with other studies we found that hepatic $\gamma$-Bbh mRNA expression and activity was significantly lower at early postnatal development in rat pups $[19,28]$. Young neonates are highly dependent on exogenous sources of L-carnitine, which is usually supplied in sufficient amounts by the breast milk during nursing [29]. Interestingly, L-carnitine levels in the milk of nursing rat dams decrease significantly by mid-lactation [30,31]. Despite the reduced exogenous L-carnitine, serum free L-carnitine levels in rat pups increase with advancing age [27]. The maturation of hepatic $\gamma$-Bbh contributes to the postnatal increase in L-carnitine levels in the body. However, our study also suggests that maturation of 

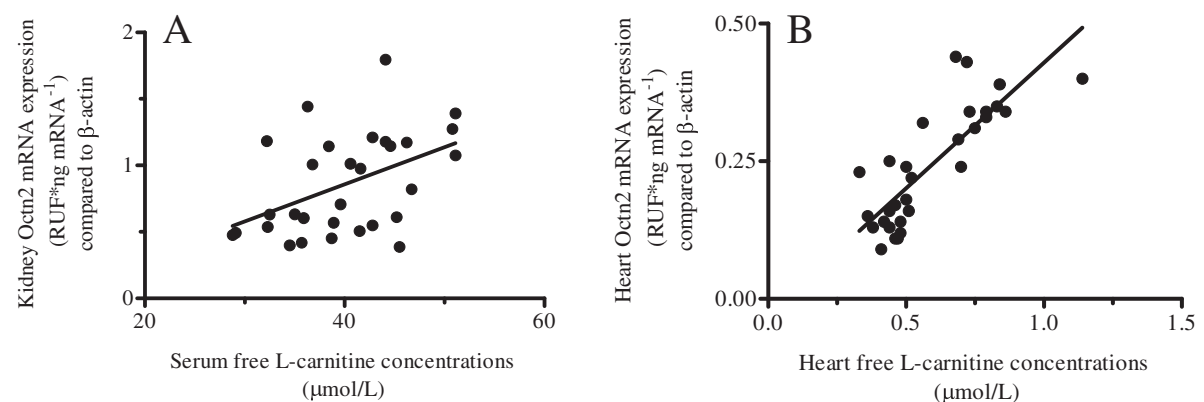

Figure 3 (A) Correlation between rat kidney Octn2 mRNA expression and serum free L-carnitine concentration (Pearson's $r=0.462$ ).

(B) Correlation between heart Octn2 mRNA expression and heart free L-carnitine concentration (Pearson's $r=0.823$ ).

other processes, namely gastrointestinal absorption and renal reabsorption of L-carnitine additionally contributed to the postnatal rise in serum L-carnitine.

Absorption of dietary sources of L-carnitine requires the function of several transporter systems expressed at the gastrointestinal epithelial barrier [25]. In our study expression of small intestinal Octn2 and Octn3 did not change with postnatal development, while Octn1 expression increased significantly between PD4 to PD8 remaining relatively constant after PD8. A previous study, which examined the postnatal maturation of the intestinal uptake L-carnitine, noted that $\mathrm{Na}^{+}$-dependent and $\mathrm{Na}^{+}$-independent intestinal uptake of L-carnitine was high in late gestation and in the newborn and significantly decreased between PD1 and PD15 [32]. Furthermore, mRNA expression of Octn2 demonstrated only a $20 \%$ decrease between PD1 and PD15 in the jejunum, while ileal expression demonstrated a $100 \%$ decrease between these two postnatal age groups [32]. In our study Octn2 mRNA expression was evaluated in the jejunum, and the constant expression of Octn2 and Octn3 is consistent with these findings. Octn2 and Octn3 mediates the $\mathrm{Na}^{+}$-dependent uptake of L-carnitine at the small intestine $[11,33]$, and although not statistically significant, our data demonstrates that Octn2 expression did decrease at PD11 and PD20 and Octn3 at PD20, which might suggest a reduced ability to absorb L-carnitine with advancing postnatal age as previously reported [32].

Renal reabsorption of L-carnitine from the urinary filtrate plays a significant role in maintenance of L-carnitine levels in the body. Almost $95 \%$ of the excreted L-carnitine is reabsorbed by transporters expressed in the proximal tubules of the kidney with Octn2 as the principal transporter involved in this process [12]. In our study renal Octn2 expression increased during postnatal development in the rat, which is consistent with the literature $[12,14,34]$. The increase in renal Octn2 expression correlated strongly with increases in serum L-carnitine levels suggesting that renal Octn2 plays a significant role in the postnatal pattern of serum L-carnitine development. Overall our data suggest the developmental changes in hepatic $\gamma$-Bbh expression, intestinal Octn1 expression, and renal Octn2 expression might systemically contribute to the postnatal increase in serum L-carnitine levels. However, the precise interconnections of these pathways and their overall contribution to L-carnitine homeostasis during development is
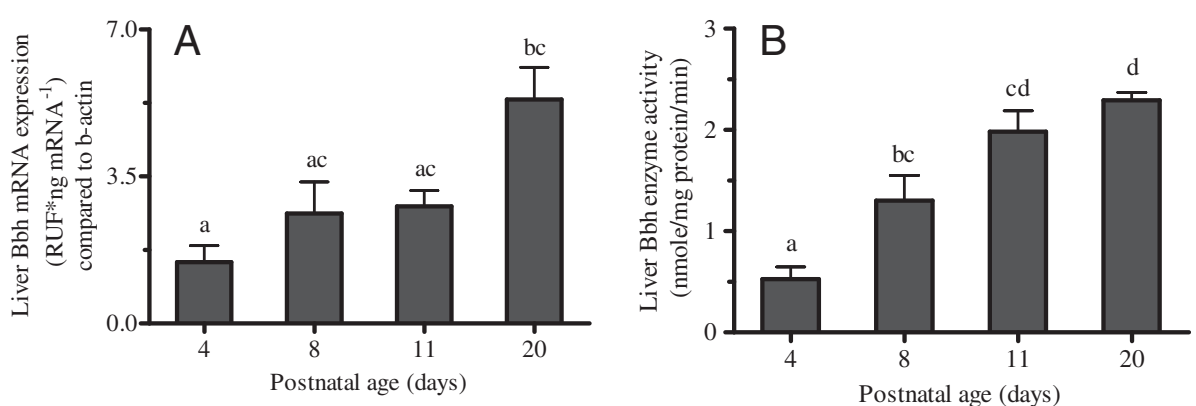

Figure 4 Mean \pm SEM rat liver gamma-butyrobetaine hydroxylase (Bbh) (A) mRNA expression and (B) activity at postnatal day 4, 8, 11, and $20(n=6)$. mRNA expression was normalized to $\beta$-actin and fold difference (FD) was determined by using $2^{-\Delta \Lambda C T}$ method. Bbh activity was measured by quantifying the conversion of $\gamma$-butyrobetaine to L-carnitine by HPLC-UV. One-way ANOVA with Tukey's post hoc test was used for the comparisons between ages and bars with the same letters indicate no significant difference, $P<0.05$. 

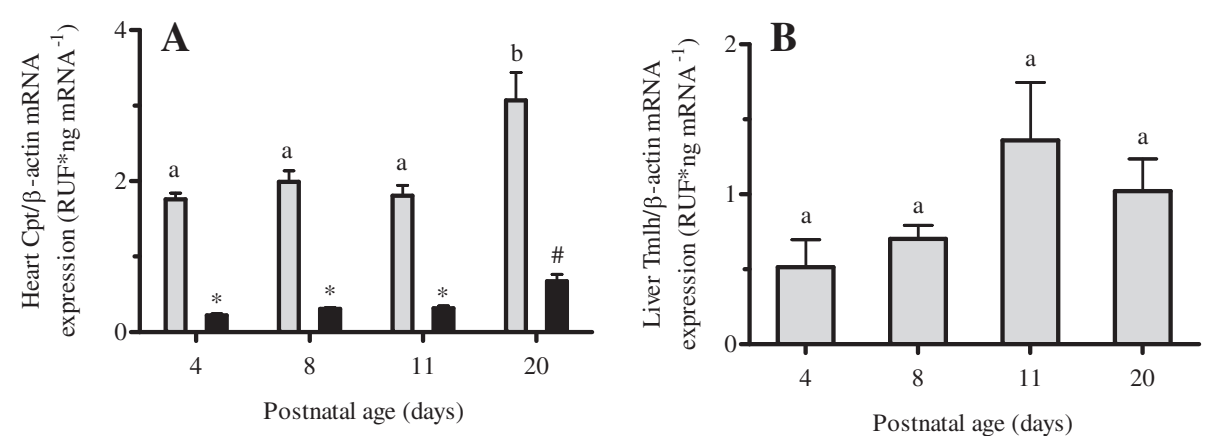

Figure 5 Mean \pm SEM mRNA expression of (A) heart carnitine palmitoyltransferase $1 \mathrm{~b}$ (Cpt1b) (light grey bar) and carnitine palmitoyltransferase 2 (Cpt2) (black bar), and (B) hepatic trimethyllysine hydroxylase (Tmlh) in rat pups at postnatal day 4, 8, 11, and $20(\mathbf{n}=\mathbf{6})$. mRNA expression was normalized to $\beta$-actin and fold difference (FD) was determined by using $2^{-\Delta \Delta C T}$ method. One-way ANOVA with Tukey's post hoc test was used for the comparisons between ages and bars with the same letters (mRNA expression levels) or same symbol (activity levels) indicate no significant difference, $P<0.05$.

not known and further studies are required to clarify their contributions.

The distribution of L-carnitine in the body is organ dependent with the highest concentration of L-carnitine in the heart [35]. In our study, heart L-carnitine levels increased during postnatal development and these increases were correlated with increased expression of Octn2 in the heart. L-Carnitine has a significant function in energy production in neonatal cardiac tissue due to its role in fatty oxidation and the reliance of neonatal hearts on fatty acids as the primary energy substrate [36]. The dramatic increase in fatty acid oxidation rates in early heart development after birth has been attributed to an increase in L-carnitine levels [36]. Although we observed a significant increase in L-carnitine levels in

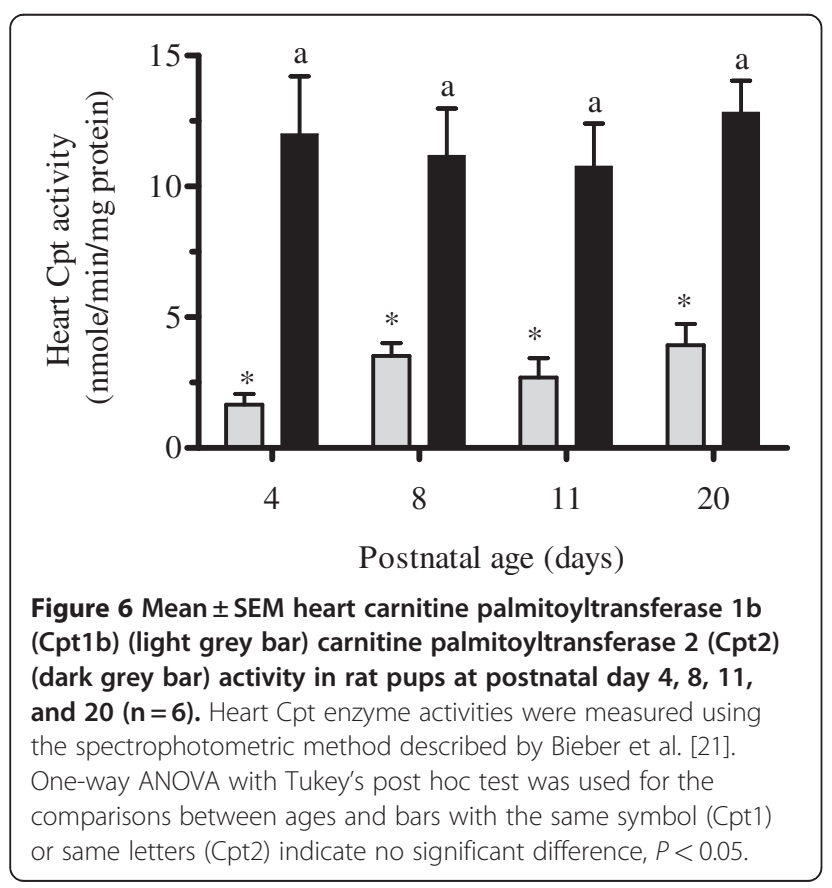

the heart with advancing age of the neonate, cardiac ATP levels remained constant through postnatal development. Interestingly, we found that creatine and ADP levels were ontogenically regulated during postnatal development. The significance of such developmental changes is not clear and requires investigation.

We also evaluated heart Cpt enzyme expression and activity due to the pivotal role of these enzymes in heart energy production. The postnatal increase in both Cpt1b and Cpt 2 mRNA expression at postnatal day 20 are paralleled by the increases in heart L-carnitine concentrations. Indeed, Cpt1a and Cpt2 mRNA levels were increased by carnitine administration in cell culture systems [37]. Thus, the significant increase in heart L-carnitine levels at postnatal day 20 might account for

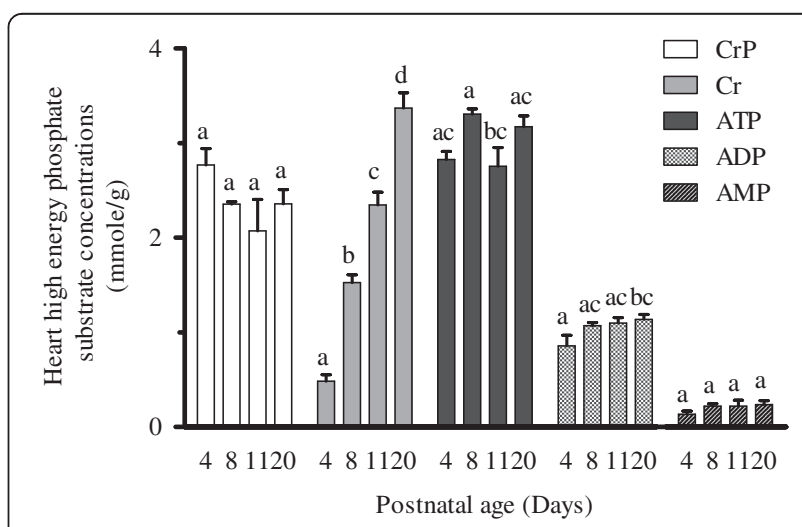

Figure 7 Mean \pm SEM heart high-energy phosphate substrate concentration in rat pups at postnatal day 4, 8, 11, and 20 $(\mathbf{n}=\mathbf{6})$. The heart high energy phosphate substrate levels including creatine $(\mathrm{Cr})$, creatine phosphate (CrP), ATP, ADP and AMP were measured with HPLC-UV method as described by Olkowski et al. [24]. One-way ANOVA with Tukey's post hoc test was used for the comparisons between ages and bars with the same symbol indicate no significant difference, $P<0.05$. ( $\mathrm{Cr}$ - creatine; $\mathrm{CrP}$ - creatine phosphate). 
the transcriptional enhancement of both $\mathrm{Cpt} 1 \mathrm{~b}$ and Cpt2. Despite these transcriptional increases in Cpt enzymes, we observed no significant changes in heart Cpt enzyme activity. Cpt enzyme activities have been reported to increase with increasing mitochondrial L-carnitine levels [38-40]. Unfortunately, L-carnitine levels in the whole heart tissue rather than in the mitochondria were measured in our study.

In conclusion, several L-carnitine homeostasis pathways underwent significant ontogenesis during postnatal development in the rat. However, the exact relationship between these pathways and their contribution to L-carnitine homeostasis during development is not completely known and further studies are required to clarify their contributions. Such a clarification is necessary to understand the impact of exogenous and endogenous factors on L-carnitine status during development. Nonetheless, this systematic evaluation of key pathways in the L-carnitine homeostasis pathway provides a basis from which we can conduct further evaluations regarding the effects of exogenous (i.e. drug) and endogenous factors (i.e. disease) on L-carnitine status during postnatal development and possible long-term consequences of any disturbance in the normal ontogeny of these pathways.

\begin{abstract}
Abbreviations
Bbh: -butyrobetaine hydroxylase (Bbh); Cpt: Carnitine palmitoyltransferase; Tmlh: Trimethyllysine hydroxylase; Octn: Organic cation/carnitine transporter; QRT-PCR: Quantitative reverse transcription-polymerase chain reaction, DTNB, 5,5'-dithio-bis (2-nitrobenzoic acid) (DTNB); PD: Postnatal day; Cr: Creatine (Cr); CrP: Creatine phosphate; ATP: Adenosine triphosphate; ADP: Adenosine diphosphate; AMP: Adenosine monophosphate.
\end{abstract}

\section{Competing interesting}

The authors declare that they have no competing interest.

\section{Acknowledgments}

This study was funded by a Rexall Research Trust Fund Grant, College of Pharmacy and Nutrition, University of Saskatchewan.

\section{Author details}

${ }^{1}$ College of Pharmacy and Nutrition, University of Saskatchewan, 110 Science Place, Saskatoon, SK S7N 5C9, Canada. ${ }^{2}$ Toxicology Centre, University of Saskatchewan, 44 Campus Drive, Saskatoon, SK S7N 5B3, Canada.

\section{Author's contributions}

All authors contributed substantially to the body of work and have read and approved the final submitted manuscript.

Received: 22 February 2012 Accepted: 17 July 2012

Published: 17 July 2012

\section{References}

1. Borum PR: Role of carnitine during development. Can J Physiol Pharmacol 1985, 63(5):571-576.

2. Sharma S, Black SM: Carnitine Homeostasis, Mitochondrial Function, and Cardiovascular Disease. Drug Discov Today Dis Mech 2009, 6(1-4):e31-e39.

3. Giovannini M, Agostoni C, Salari PC: Is carnitine essential in children? J Int Med Res 1991, 19(2):88-102.

4. Rebouche $\mathrm{CJ}$ : Kinetics, pharmacokinetics, and regulation of L-carnitine and acetyl-L-carnitine metabolism. Ann N Y Acad Sci 2004, 1033:30-41.

5. Novak M, Wieser PB, Buch M, Hahn P: Acetylcarnitine and free carnitine in body fluids before and after birth. Pediatr Res 1979, 13(1):10-15.
6. Rebouche CJ, Engel AG: Tissue distribution of carnitine biosynthetic enzymes in man. Biochim Biophys Acta 1980, 630(1):22-29.

7. Rovamo LM, Salmenpera L, Arjomaa P, Raivio KO: Carnitine during prolonged breast feeding. Pediatr Res 1986, 20(8):806-809.

8. Rebouche CJ: Carnitine movement across muscle cell membranes. Studies in isolated rat muscle. Biochim Biophys Acta 1977, 471(1):145-155.

9. Davis AT: Fractional contributions to total carnitine in the neonatal rat. J Nutr 1989, 119(2):262-267.

10. Duran JM, Peral MJ, Calonge ML, Ilundain AA: Functional characterization of intestinal L-carnitine transport. J Memb Biol 2002, 185(1):65-74.

11. Duran JM, Peral MJ, Calonge ML, Ilundain AA: OCTN3: A $\mathrm{Na}+-$-independent L-carnitine transporter in enterocytes basolateral membrane. J Cell Physiol 2005, 202(3):929-935.

12. Tamai I, China K, Sai Y, Kobayashi D, Nezu J, Kawahara E, Tsuji A: Na (+)-coupled transport of L-carnitine via high-affinity carnitine transporter OCTN2 and its subcellular localization in kidney. Biochim Biophys Acta 2001, 1512(2):273-284.

13. Tamai I, Ohashi R, Nezu Jl, Sai Y, Kobayashi D, Oku A, Shimane M, Tsuji A: Molecular and functional characterization of organic cation/carnitine transporter family in mice. J Biol Chem 2000, 275(51):40064-40072.

14. Alnouti Y, Petrick JS, Klaassen CD: Tissue distribution and ontogeny of organic cation transporters in mice. Drug Metab Dispos 2006, 34 (3):477-482.

15. Garcia-Delgado M, Peral MJ, Duran JM, Garcia-Miranda P, Calonge ML, Ilundain AA: Ontogeny of $\mathrm{Na}(+) / \mathrm{L}$-carnitine transporter and of gammatrimethylaminobutyraldehyde dehydrogenase and gammabutyrobetaine hydroxylase genes expression in rat kidney. Mech Ageing Dev 2009, 130(4):227-233.

16. Bressler $R$, Brendel $K$ : The role of carnitine and carnitine acyltransferase in biological acetylations and fatty acid synthesis. J Biol Chem 1966, 241 (17):4092-4097.

17. Kerner J, Hoppel C: Carnitine palmitoyltransferase-I and regulation of mitochondrial fatty acid oxidation. Monatsh Chem 2005, 136:1311-1323.

18. Woldegiorgis G, Dai J, Arvidson D: Structure-function studies with the mitochondrial carnitine palmitoyltransferases I and II. Monatsh Chem 2005, 136:1325-1340.

19. Hahn P: The development of carnitine synthesis from gammabutyrobetaine in the rat. Life Sci 1981, 28(9):1057-1060.

20. Feng Y, Zhang S, Xu Y, Zhoum J, Tao Y, Cai W: Study on determination of carnitine in serum by HPLC. Acta Nutrimenta Sin 2006, 28:177-179.

21. Bieber $L L$, Abraham $T$, Helmrath $T$ : A rapid spectrophotometric assay for carnitine palmitoyltransferase. Anall Biochem 1972, 50(2):509-518.

22. Alhomida AS: Oral theophylline changes renal carnitine palmitoyltransferase activity in rats. Arch Med Res 2001, 32(5):394-399.

23. Mayer-Davis EJ, Rifas-Shiman SL, Zhou L, Hu FB, Colditz GA, Gillman MW: Breast-feeding and risk for childhood obesity: does maternal diabetes or obesity status matter? Diabetes Care 2006, 29(10):2231-2237.

24. Olkowski AA, Nain S, Wojnarowicz C, Laarveld B, Alcorn J, Ling BB: Comparative study of myocardial high energy phosphate substrate content in slow and fast growing chicken and in chickens with heart failure and ascites. Comp Biochem Physiol Part A, Mol Integr Physiol 2007, 148(1):230-238.

25. Arenas J, Rubio JC, Martin MA, Campos Y: Biological roles of L-carnitine in perinatal metabolism. Early Hum Dev 1998, 53(Suppl):S43-S50.

26. Nakano C, Takashima S, Takeshita K: Carnitine concentration during the development of human tissues. Early Hum Dev 1989, 19(1):21-27.

27. Peschechera A, Scalibastri M, Russo F, Giarrizzo MG, Carminati P, Giannessi F, Arduini A, Ricciolini R: Carnitine depletion in rat pups from mothers given mildronate: a model of carnitine deficiency in late fetal and neonatal life. Life Sci 2005, 77(24):3078-3091.

28. Galland S, Le Borgne F, Bouchard F, Georges B, Clouet P, Grand-Jean F, Demarquoy J: Molecular cloning and characterization of the cDNA encoding the rat liver gamma-butyrobetaine hydroxylase. Biochim Biophys Acta 1999, 1441(1):85-92.

29. Melegh B, Kerner J, Sandor A, Vinceller M, Kispal G: Oral L-carnitine supplementation in low-birth-weight newborns: a study on neonates requiring combined parenteral and enteral nutrition. Acta Paediatr Hung 1986, 27(3):253-258.

30. Ling B, Alcorn J: Acute administration of cefepime lowers L-carnitine concentrations in early lactation stage rat milk. J Nutr 2008, 138(7):1317-1322. 
31. Robles-Valdes C, McGarry JD, Foster DW: Maternal-fetal carnitine relationship and neonatal ketosis in the rat. J Biol Chem 1976, 251 (19):6007-6012.

32. Garcia-Miranda P, Duran JM, Peral MJ, llundain AA: Developmental maturation and segmental distribution of rat small intestinal L-carnitine uptake. J Membr Biol 2005, 206(1):9-16.

33. Kato $Y$, Sugiura M, Sugiura T, Wakayama T, Kubo Y, Kobayashi D, Sai Y, Tamai I, Iseki S, Tsuji A: Organic cation/carnitine transporter OCTN2 (Slc22a5) is responsible for carnitine transport across apical membranes of small intestinal epithelial cells in mouse. Molec Pharmacol 2006, 70 (3):829-837.

34. Klaassen $C D$, Aleksunes $L M$ : Xenobiotic, bile acid, and cholesterol transporters: function and regulation. Pharmacol Rev 2010, 62(1):1-96.

35. Lohninger A, Pittner G, Pittner F: L-Carnitine: New aspects of a known compound - A brief survey. Chem Mon 2005, 136:1255-1268.

36. Onay-Besikci A, Campbell FM, Hopkins TA, Dyck JR, Lopaschuk GD: Relative importance of malonyl $\mathrm{CoA}$ and carnitine in maturation of fatty acid oxidation in newborn rabbit heart. Am J Physiol Heart Circ Physiol 2003, 284(1):H283-H289.

37. Godarova A, Litzlbauer E, Brunner S, Agu AC, Lohninger A, Hofbauer R: L-Carnitie regulates mRNA expression levels of the carnitine acyltransferases - CPT1A, CPT2 and CRAT. Chem Mon 2005, 136:13491363.

38. Girard J, Duee PH, Ferre P, Pegorier JP, Escriva F, Decaux JF: Fatty acid oxidation and ketogenesis during development. Reprod Nutr Dev 1985, 25(1B):303-319.

39. Lin X, House R, Odle J: Ontogeny and kinetics of carnitine palmitoyltransferase in liver and skeletal muscle of the domestic felid (Felis domestica). TJ Nutr Biochem 2005, 16(6):331-338.

40. Penas $\mathrm{M}$, Benito $\mathrm{M}$ : Regulation of carnitine palmitoyltransferase activity in the liver and brown adipose tissue in the newborn rat: effect of starvation and hypothermia. Biochem Biophys Res Commun 1986, 135 (2):589-596.

doi:10.1186/1743-7075-9-66

Cite this article as: Ling et al: Systematic Evaluation of Key L-Carnitine Homeostasis Mechanisms during Postnatal Development in Rat. Nutrition \& Metabolism 2012 9:66.

\section{Submit your next manuscript to BioMed Central and take full advantage of:}

- Convenient online submission

- Thorough peer review

- No space constraints or color figure charges

- Immediate publication on acceptance

- Inclusion in PubMed, CAS, Scopus and Google Scholar

- Research which is freely available for redistribution 